\title{
Development of the Workplace Health Savings Calculator: a practical tool to measure economic impact from reduced absenteeism and staff turnover in workplace health promotion
}

\author{
Siyan Baxter ${ }^{1 *}$, Sharon Campbell ${ }^{2}$, Kristy Sanderson ${ }^{1}$, Carl Cazaly ${ }^{2}$, Alison Venn ${ }^{1}$, Carole Owen ${ }^{2}$
} and Andrew J. Palmer ${ }^{1}$

\begin{abstract}
Background: Workplace health promotion is focussed on improving the health and wellbeing of workers. Although quantifiable effectiveness and economic evidence is variable, workplace health promotion is recognised by both government and business stakeholders as potentially beneficial for worker health and economic advantage. Despite the current debate on whether conclusive positive outcomes exist, governments are investing, and business engagement is necessary for value to be realised. Practical tools are needed to assist decision makers in developing the business case for workplace health promotion programs. Our primary objective was to develop an evidence-based, simple and easy-to-use resource (calculator) for Australian employers interested in workplace health investment figures.

Results: Three phases were undertaken to develop the calculator. First, evidence from a literature review located appropriate effectiveness measures. Second, a review of employer-facilitated programs aimed at improving the health and wellbeing of employees was utilised to identify change estimates surrounding these measures, and third, currently available online evaluation tools and models were investigated. We present a simple web-based calculator for use by employers who wish to estimate potential annual savings associated with implementing a successful workplace health promotion program. The calculator uses effectiveness measures (absenteeism and staff turnover rates) and change estimates sourced from 55 case studies to generate the annual savings an employer may potentially gain. Australian wage statistics were used to calculate replacement costs due to staff turnover. The calculator was named the Workplace Health Savings Calculator and adapted and reproduced on the Healthy Workers web portal by the Australian Commonwealth Government Department of Health and Ageing.
\end{abstract}

Conclusion: The Workplace Health Savings Calculator is a simple online business tool that aims to engage employers and to assist participation, development and implementation of workplace health promotion programs.

Keywords: Workplace health promotion, Health economics, Return on investment, Calculator, Absenteeism, Staff turnover, Productivity, Workplace, Employee, Policy-research collaboration

\footnotetext{
*Correspondence: siyan.baxter@utas.edu.au

${ }^{1}$ Menzies Institute for Medical Research, University of Tasmania, Medical

Science 2 Building, 17 Liverpool St, Private Bag 23, Hobart, TAS 7000,

Australia

Full list of author information is available at the end of the article
} 


\section{Background}

Improving the health and wellbeing of workers is firmly on the public health and business agenda. The World Health Organisation (WHO) has identified the workplace as a target setting for health promotion [1], and formed a Global Plan of Action on Workers' Health (2008-2017) [2] to protect and promote health at work and respond to the health needs of the working population. Endorsement of this action plan is evidenced in the emergent company and society-wide shift to include workplace health promotion as a key strategy. Consequently, workplace health has gained profile as a strategic asset to economies, as revealed in various international reports and policy guidelines [3-9]. This stands, despite recent inconclusive reviews on whether health and economic outcomes are positive, negative or neutral [10-13], and an extensive review that demonstrated economic evidence, although improving over time, is low to moderate in methodological quality [14]. Nonetheless, the evidence that healthy employees provide social and economic benefits to businesses and the community continues to be largely accepted. These include reductions in absenteeism from illness and injury, increased productivity, reduced staff turnover, reduction in health care costs and a more satisfied work force [14-17].

Health economics offers an analytical technique to measure the financial impact of health-promoting initiatives in order to assess allocation efficiency and determine whether or not an intervention is worthwhile. Although it is important for government, organisations and businesses to accurately measure the rate of return on investments, the application of health economic theory in workplace health is steeped in methodological complexities [14]. Primarily, economic evaluations focus on indicators of business performance and health change targets. Although tools such as workplace health calculators are available for decision makers who wish to create a business case for workplace health, those that currently exist online have been developed from evidence arising out of the Unites States and the United Kingdom with financial estimates available in British pound $[18,19]$ and United States dollar [20], and the latter only suitable to businesses with greater than 1000 employees based in US, Europe, India and China. Little is available to assist other jurisdictions in the business case for workplace health, both in terms of currency output and simple translation, and as a result, the adoption of these existing online-calculators can be problematic.

In 2009 the Australian Government established the National Partnership Agreement on Preventive Health initially promising an investment of $\$ 221.8$ million over nine years (2009-2010 to 2017-2018) [8]. This commitment provided funding to all states and territories to support the Healthy Workers Initiative and enabled Australian health policy-makers to engage in a common mission to improve and maintain the health and wellbeing of workers. With this support, a Healthy Workers Initiative project team was developed within Population Health Services in the Tasmanian Department of Health and Human Services. One of the many objectives of the project team was to develop an evidence-based, simple and easy-to-use resource (calculator) for Australian employers interested in workplace health investment figures, and make this available through the Healthy Workplace Resource Toolkit.

This paper describes the development of the Workplace Health Savings Calculator, a toolkit output that is currently available online.

\section{Data collection}

Data were collected in three phases (1) locate appropriate effectiveness measures, (2) identify change estimates surrounding these measures and (3) decide on an appropriate model.

To satisfy the first phase, a literature review was being performed by SB, AP, KS and AV (the researchers) at the time the Healthy Worker Initiative project team members SC and CO approached with the question "What is the evidence-based business case for workplace health promotion?" A partnership agreement was established and researchers utilised their concurrent literature search for the purposes of providing economic evidence to assist the development of the Healthy Workplace Resource Toolkit. The search was conducted in relevant economic and biomedical databases between November 2011 and January 2012. In addition, a keyword search using Google Scholar and a manual search of citations from relevant papers was undertaken to locate published evidence on the financial impact of workplace health promotion. The search strategy has been published along with the review [14]. Information gained from this review was utilised to ascertain measures of effectiveness which contextually provided transferability and generalisability to the Australian sector. Two measures of effectiveness were recognised as business metrics most readily captured in operations. These were worker 'absenteeism' and 'staff turnover. Both were adopted as the key performance estimates for the calculator.

The second requirement in the development phase was to establish the magnitude of possible change in absenteeism and staff turnover as a result of implementing a workplace health program. These estimates of change for absenteeism and staff turnover were sourced from a second review study [21] which readers can refer to for additional information. This review, published in 2008, was commissioned by the Health Work Wellbeing Executive 
in England and undertaken by PriceWaterhouseCoopers LLP. Under the constraints identified in the first review, namely, that no Australian equivalent published data source existed, that volume of publications from the United States far exceeded that from jurisdictions operating under a national health care system, and that large variability in both estimates and methodological quality of studies prevail, the authors considered this PriceWaterhouseCoopers' review to be most appropriate for our needs and of sound evidence base. Moreover, the evidence from this review is cited and supports the Workplace Wellbeing Charter [6], a national award, whose "standards reflect best practice" and is endorsed by Public Health England.

Finally, an internet search was conducted to locate workplace health calculators currently in existence. These were assessed for their ease of use and applicability to the Australian business context. As a result of this search, a model developed by the National Institute for Health and Clinical Excellence (NICE) [19] was considered simple to use and adapted for our purposes.

\section{Assumptions used to develop the tool}

In developing the tool, the following assumptions were made. First, 'absenteeism' (or 'sick leave') was defined as an employee's unplanned leave from work, not including other leave such as carer's leave or maternity leave. Examples of unplanned leave would be due to illnesses such as colds and flu.

Second, a workplace health promotion program was considered 'successful' when it was designed to target the needs of employees, when participation rates were reasonable (greater than $25 \%$ participation), and the program was actively supported by senior management and leaders within the organisation.

Third, different types of workplace health promotion interventions (health and safety, disease management, and health promotion-the modification of risk behaviours such as smoking, nutrition, physical activity and stress to improve overall employee wellbeing) contributed equally, and were linked to the improvement of the effectiveness estimates.

Last, calculated savings were assumed to be a longterm benefit. It is evidenced in the literature that positive effects on absenteeism and staff turnover occur between 2 and 5 years post implementation of a successful workplace health program [22].

The PriceWaterhouseCoopers' review [21], from which the magnitude of change for absenteeism and staff turnover was sourced, included 55 case studies from organisations in the United Kingdom that implemented a variety of workplace health promotion programs. The case studies were submitted to the Health Work Wellbeing
Executive and PricewaterhouseCoopers LLP was commissioned to undertake a review including interviews with selected organisations. Overall, 45 case studies reported evidence on change related to absenteeism and 18 on staff turnover, with 28 (51\%) providing evidence from behaviour modification or lifestyle programs such as smoking cessation, healthy diet and subsidised exercise programmes. These interventions focussed on similar behavioural and lifestyle health risk change targets to those encouraged in Australia, which are commonly referred to as SNAPS (smoking, nutrition, alcohol, physical activity, stress) interventions [23]. There were 32 case studies (58 \%) focussed on occupational health and safety interventions. The data were collected from businesses within nine different industries; defined as manufacturing, finance, public service, utilities, business services, construction/engineering, retail, education, and others. Company size and intervention type by industry group for all case studies is provided in Appendix 2b of the source review [21]. Their diversity represented a good range of industry types relevant to Australia, with national statistics identifying the vast majority of Australian businesses operate in the service sectors (construction, professional/scientific/technical, retail trade, education, accommodation, transport, and utilities), with the remaining in manufacturing, mining agriculture/forestry and fishing [24]. Further similarities between these two nations such as the proportion of small to medium businesses, population demographics and drivers for workplace health promotion are shown in Table 1.

Global trends in employer wellbeing strategies and practices were reported in 2014 [25]. Data were collected from 37 countries (in 11 languages) that included 1041 employer-participants (8 million employees) across all industry categories. Although it documented similarities between Australia/New Zealand and Europe in terms of percentages of organisations offering health promotion, health risk drivers (namely stress, physical activity, nutrition), and types of program components, no evidence relating to differences in effect size between countries was obtained. There is paucity in the literature surrounding between-country magnitudes of effect in workplace health promotion. Consequently, within the calculator, functionality allows change estimates for absenteeism and staff turnover to be edited by the user, and the default figure represents the lowest effectiveness estimate from the range reported in the UK PricewaterhouseCoopers' review. Refer to Table 2 for change estimates and ranges. This most conservative approach acknowledges that these benefits may not be fully transferable to the Australian context.

When an average effectiveness estimate was reported, it was assumed the average was an average across the 


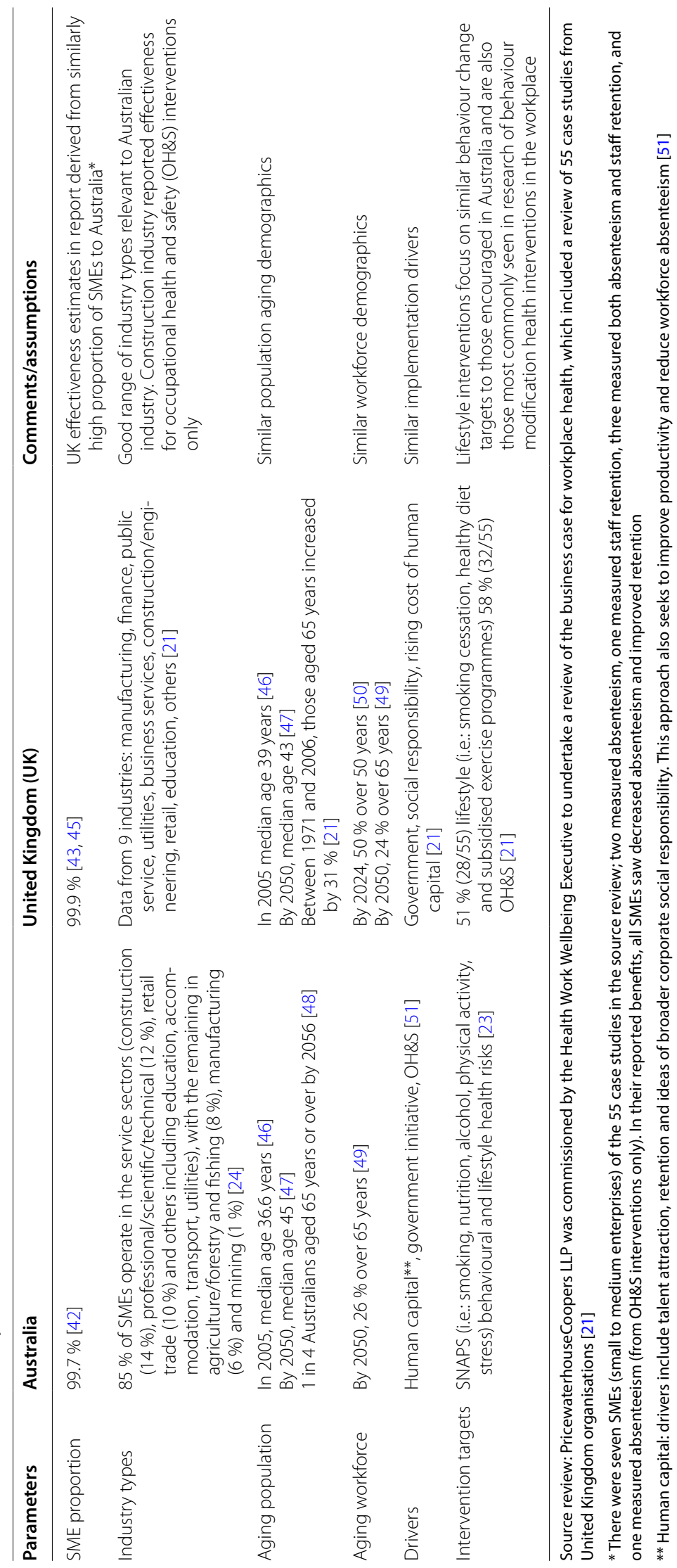


Table 2 Change estimates used within the Workplace Health Savings Calculator

\begin{tabular}{|c|c|c|c|}
\hline Change estimate & Source & Measurement & Assumption \\
\hline $\begin{array}{l}\text { Absenteeism } \\
\text { (\% decrease) }\end{array}$ & PWC $2008[21]^{\mathrm{a}}$ & Average $30-40 \%$ reduction, based on $45 / 55$ case studies & $\begin{array}{l}\text { The other } 10 \text { studies did not measure the } \\
\text { perceived benefits of } A B \text {, so average holds } \\
\text { for all that do }\end{array}$ \\
\hline $\begin{array}{l}\text { Staff turnover } \\
\text { (replacement } \\
\text { cost) }\end{array}$ & ABS $2008[26]$ & $\begin{array}{l}\text { 75-150 \% salary as replacement cost } \\
\text { Industry types: engineering, construction, professional services } \\
\text { (e.g.: finance, admin), public service, resources (e.g.: agriculture, } \\
\text { mining) retail and entertainment }\end{array}$ & $\begin{array}{l}75 \% \text { a conservative assumption used in } \\
\text { place of conclusive evidence }\end{array}$ \\
\hline $\begin{array}{l}\text { Staff turnover (\% } \\
\text { decrease) }\end{array}$ & PWC 2008 [21] & $\begin{array}{l}\text { 10-25 \% decrease in staff turnover, based on 18/55 case studies. } \\
\text { On average this retention range was 20-25\% (from } 4 \text { industry } \\
\text { categories: finance, utilities, business service, and other) }\end{array}$ & $\begin{array}{l}\text { That } 37 \text { case studies did not report on turno- } \\
\text { ver, average based on the } 18 \text { studies that } \\
\text { did. Average holds as an average for all }\end{array}$ \\
\hline
\end{tabular}

a These were extracted from the source review [21] of 55 case studies that had varying durations of implementation. It has been shown in the literature that benefits from reduced absenteeism and staff turnover may not be realised before 2 and 5 years after implementation of a successful workplace health promotion program [22]. We wish to reiterate an assumption outlined in this study that the calculated potential annual savings is a long-term benefit

case studies that measured that particular effectiveness outcome. It was therefore presumed the average would apply for any business that measured these particular outcomes after implementation of a workplace health promotion program.

In concluding the assumptions used to develop the Workplace Health Savings Calculator, this tool is considered by the authors to be most appropriate for use in Australia, on the following basis; (1) input estimates for absenteeism and staff turnover are generated by the Australian user company, (2) cost estimates are derived using Australian wage statistics, and (3) change estimates from the PriceWaterhouseCoopers' review are (a) most conservative and (b) generalizable to the Australian business context. The Workplace Health Savings Calculator specifically does not attempt to measure or quantify in dollar value any additional health benefits that may be enjoyed by employees undertaking health promotion in their workplace; as such estimates remain elusive in the literature [14].

\section{Description of user interface}

The calculator was adapted from a model developed by the National Institute for Health and Clinical Excellence (NICE) [19], and consists of three tabs (Fig. 1). The first allows the user to input relevant data on employee numbers and salary, the second to input data on staff turnover, and the third tab calculates the total potential annual savings that arise from the implementation of a successful workplace health promotion program. Below the savings output on this third and final tab is an organisational profile box which users have the option to complete and submit (Fig. 2). The submitting user maintains anonymity of the company name yet provides the site administrator with base level information about the company, such as industry type, business size and locality. Lastly, for users who wish to identify themselves, there is an option at the bottom of the box to submit an email via a 'Contact us' hyperlink.

For companies whose staffing profile does not solely consist of full-time employees, an additional feature was added to account for part-time and casual positions. For these businesses, where total number of full-time equivalent hours may not be recorded, there is an option within the calculator that allows the user to input 'total number of sick days in the last 12 months' instead of 'total number of employees.' This feature simplifies the data gathering process, and allows users to choose between two algorithms in order to estimate, with minimal burden, the total annual savings in sick leave achievable by implementing a successful workplace health and wellbeing program.

Tabs one and two use effectiveness estimates to derive savings that arise from reduced absenteeism and staff turnover, which is defaulted to the most conservative estimates and can be overridden by the user. It was envisioned that the default estimates may be overridden by companies that are already implementing a program for which company-specific evaluation data were available, and for whom an online-generated calculation of annual savings offered some utility.

The effectiveness estimates within the calculator are sourced from the PriceWaterhouseCoopers' review [21] and Australian wage statistics [26]. These were absenteeism rates, which reduce by an average of 30-40\% [21]; staff turnover rates, which decrease by $10-25 \%$ [21]; and replacement cost due to staff turnover, which ranged from 75 to $150 \%$ of the worker's wage, an Australian national estimate [26]. There were many and various costs associated with this measure, such as costs for recruitment, training, specialist knowledge and productivity [27] which could account for the large range that was reported. In line with agreed assumptions, the most conservative estimates were used in the model 


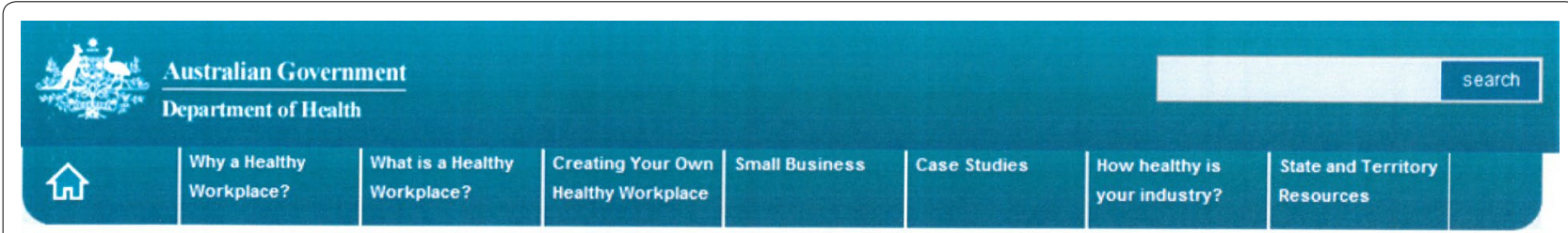

Home

\title{
Workplace Health Savings Calculator
}

\section{ABSENTEEISM STAFF TURNOVER TOTAL ANNUAL SAVINGS}

\begin{abstract}
Result: Estimate of savings by reducing sick leave and staff turnover
\end{abstract}
Savings made by reducing sick leave

$\$ 24,000$
Savings made by reducing staff turnover

$\$ 10,125$
Savings made by reducing sick leave and

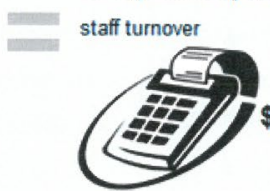

\section{preview \& print result}

Fig. 1 Workplace Health Savings Calculator as it appears on the Commonwealth Government's Department of Health, Healthy Workers web portal. The following scenario is an example of a company profile whose input would match these calculations. In the last 12 months, a company of 100 employees has experienced a sick leave rate of 4 days per employee (total annual sick days 400 ) and has recruited 3 replacement staff. The average staff salary is $\$ 45,000$. The company operates $8 \mathrm{~h}$ a day and the average hourly wage is $\$ 25$. The estimated potential savings to the company when implementing a successful workplace health and wellbeing program is set at the default effectiveness measures; a $30 \%$ reduction in sick leave and a $10 \%$ reduction in staff turnover. The cost of replacing an employee is defaulted at $75 \%$ of the annual salary

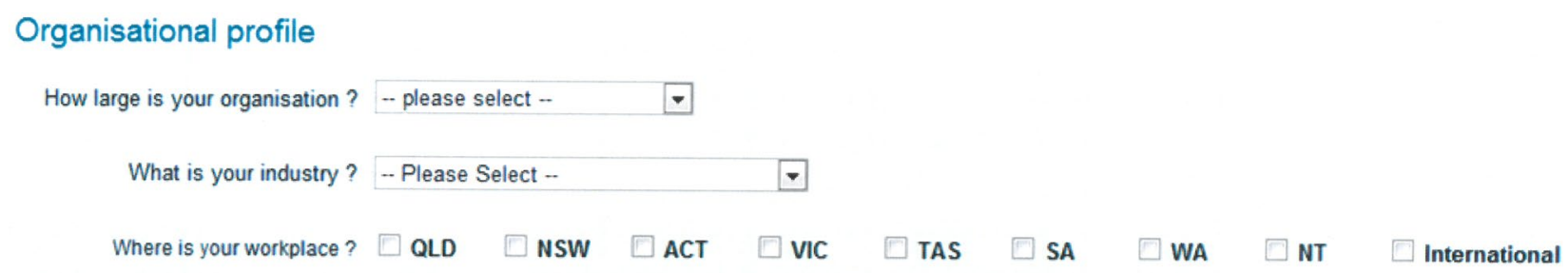

\section{Submit}

Please contact us if you would like to provide feedback on the calculator or share your workplace health promotion experiences.

Fig. 2 Screen that accompanies the Workplace Health Savings Calculator for purposes of data collection. The data is non-identifiable unless users wish to identify themselves by submitting an email via the 'Contact us' hyperlink option at the bottom of this organisational profile box

when a range of estimates were offered. Details of these change estimates used and generalisability are provided in Tables 1 and 2.

The calculator was initially published in print within the Healthy Workplace Resource Toolkit (Table 3) with an accompanying page offering an example of the algorithm (Table 4). In 2013 a Microsoft Excel spreadsheet was developed and the calculator was published on the WorkSafe Tasmania website [28].

The algorithm was later adapted and reproduced by the Australian Government Department of Health and Ageing for use on the Healthy Workers web portal, as 
Table 3 Print version of the simple Workplace Health Savings Calculator as it appeared in the Healthy Workplace Resource Toolkit

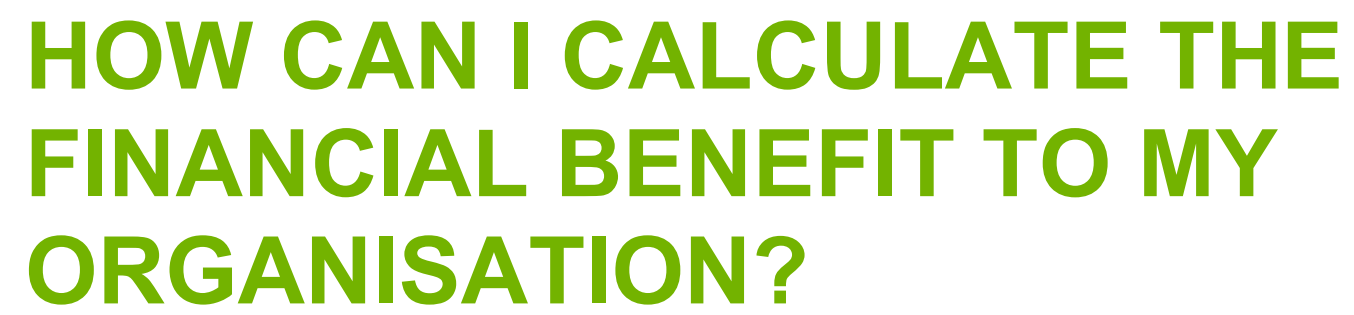

Two of the more tangible ways that employee health can have an immediate financial benefit to your organisation is through reducing:

1. Absenteeism

2. Staff turnover.

The following exercise will help you calculate the impact a successful workplace health and wellbeing program can have on staff absenteeism and turnover rates. Where a percentage range is provided, the percentage that calculates the most conservative saving is used.

\section{Absenteeism}

Fill in the following spaces to estimate the cost of absenteeism to your organisation.

Total number of employees

Sick leave rate per employee per year (in days)

OR

Total number of sick days in last 12 months

Average hours worked per day

Average hourly wage (\$)

Total annual cost of staff sick leave

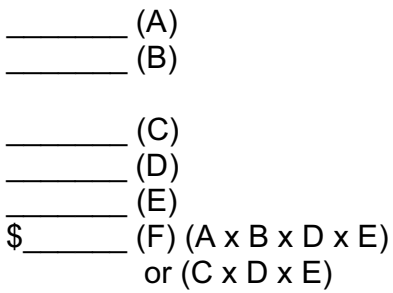

It is estimated that a successful workplace health and wellbeing program can decrease staff absenteeism by an average of $30-40 \%{ }^{21}$

Reduction in sick leave (\%)

$30 \%$

(G)

Total annual savings in sick leave achievable by

implementing a workplace health and wellbeing program

$\$$

(H) (F x G)

\section{Staff turnover}

Fill in the following spaces to estimate the cost of staff turnover to your organisation.

Total number of employees resigned in the last 12 months

Average annual gross wage (\$)

It is estimated that the cost of replacing an employee is $75-150 \%$ of the employee's salary ${ }^{26}$

Cost of replacing an employee as a percent of annual salary

$75 \%$

Annual cost of replacing employees as a result of resignation \$

(L) $(\mathrm{I} \times \mathrm{J} \times \mathrm{K})$

It is estimated that a successful workplace health and wellbeing program can decrease staff turnover by an average of $10-25 \%$. $^{21}$

Reduction in staff turnover (\%)

Total annual savings in staff turnover achievable by implementing a workplace health and wellbeing program

Total annual savings as a result of implementing a successful workplace health and wellbeing program
$10 \%$
(M)
$\$$
(N) (L x M)
$\$$
(O) $(H+N)$ 
Table 4 Example which accompanied the simple Workplace Health Savings Calculator in the Healthy Workplace Resource Toolkit

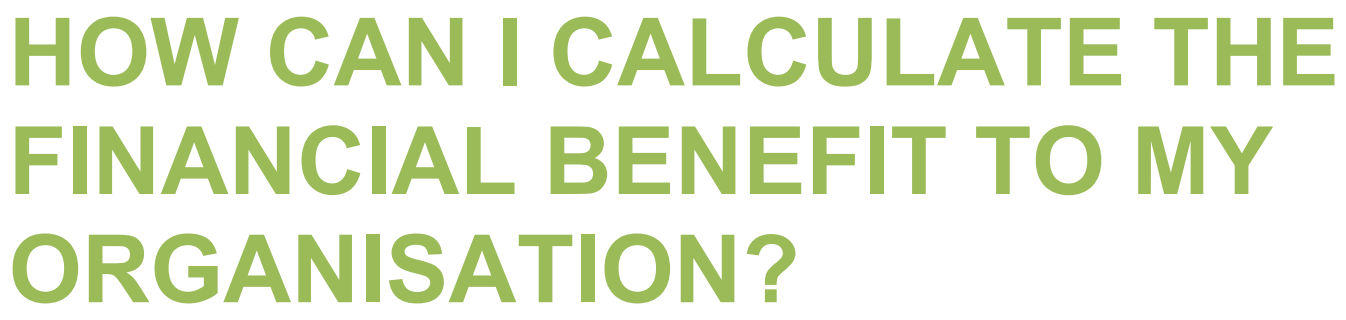

The following example illustrates these calculations.

In the last 12 months, a company of 50 staff has experienced a sick leave rate of 8.5 days per employee and has recruited 3 replacement staff due to resignations. The average staff salary is $\$ 50,000$. The company runs a shift roster of 8 -hour days and the average hourly wage is $\$ 25$.

Total number of employees

Sick leave rate per employee per year (in days)

Total number of sick days in last 12 months

Hours worked per day

Average hourly wage $(\$)$

Total annual cost of staff sick leave

Reduction in sick leave due to a workplace health and wellbeing program (\%)

Total annual savings in sick leave achievable by

implementing a workplace health and wellbeing program

Total number of employees resigned in the last 12 months

Average annual wage (\$)

Cost of replacing an employee as a percent of annual salary

Annual cost of replacing employees as a result of resignation

Reduction in staff turnover due to a workplace health and wellbeing program (\%)

Total annual savings in staff turnover achievable by

implementing a workplace health and wellbeing program

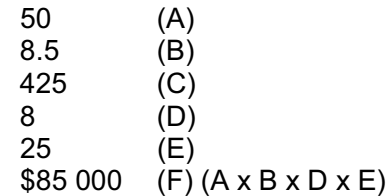

$30 \%$

(G)

$\$ 25500 \quad$ (H) $(F \times$ G)

$3 \quad(I)$

$50000 \quad(\mathrm{~J})$

$75 \% \quad(\mathrm{~K})$

$\$ 112500$ (L) (I x J x K)

$10 \% \quad(\mathrm{M})$

$\$ 11250 \quad$ (N) $(L \times M)$

Combined annual savings for reduced sick leave and staff turnover, as a result of implementing a successful workplace health and wellbeing program

$\$ 36750 \quad(0)(H+N)$

In this example, the organisation has potential annual savings of over $\$ 36000$ through minimising absenteeism and staff turnover. Other less tangible savings could be made through increased productivity, staff engagement and morale.

part of its official toolbox for the economic assessment of workplace health promotion programs. Titled "The Workplace Health Savings Calculator", it is available at: http://www.healthyworkers.gov.au on the home screen in the 'News' link (or via direct link: http://www.healthyworkers.gov.au/internet/hwi/publishing.nsf/Content/ roi-introduction).

Since its national online publication, the tool has been endorsement by an Australian non-government organisation and commercial providers of workplace health promotion and their respective networks. Further adaptions of the calculator can be viewed online [29, 30]. Evidence regarding its usability and further application are being collected through the organisational profile box and ongoing collaborator consultations. Initial data from the first year demonstrate the calculator has been accessed by a variety of businesses within the industries of Agriculture, Forestry \& Fishing; Health and Community Services; Education; Government Administration and Defence; Retail; Electricity, Gas and Water; 
and Personal and Other Services. Data also indicate these businesses are located across every state and territory in Australia, and in both metropolitan and regional areas. Two international companies have also completed the organisational profile. The majority of organisations (88\%) employed less than 200 workers of which $40 \%$ identified as small in size (1-19 employees). These initial statistics are encouraging, and not only demonstrate an interest in workplace health promotion from the Australian small-to-medium enterprise (SME) community but also across the entire country.

\section{Discussion}

The Workplace Health Savings Calculator is an online tool for estimating the economic impact of improved productivity from the implementation of a successful workplace health promotion program. It utilises a conservative set of assumptions to generate an estimate of potential annual savings. It calculates financial benefits related to reduced absenteeism and staff turnover using input estimates (number of employees, sick leave rates, average hours worked, average wage, number of resignations) that are generated at the individual company level. Annual turnover and number of employees are tangible key performance estimates most commonly measured in Australia [24]. The estimate for cost to replace staff is an Australian statistic [26]. Although commonly measured, there is a lack of Australian evidence on absenteeism and staff turnover in relation to workplace health promotion outcomes and the authors were required to carefully consider the vast and varying evidence on effectiveness and cost-effectiveness in the global literature. This was achieved in concurrence with a systematic review undertaken by the authors SB, AP, KS and AV [14]. It was considered that these two metrics (absenteeism and staff turnover) provided (1) the ease of measurement needed, and (2) best attainable estimates to attribute a dollar value, and thereby met our primary objective to develop an evidence-based, simple and easy-to-use resource (calculator) for Australian employers interested in workplace health investment figures.

Presenteeism, being present at work while suffering from a health problem that may limit job performance [31], is also linked with negative impacts to productivity and associated costs. Indeed, presenteeism accounts for greater aggregate productivity loss than absenteeism [32-34], thus decreasing worker presenteeism rates will lead to greater savings. Although preliminary evidence has shown that workplace health promotion may be effective at decreasing presenteeism rates [35], there are critical issues surrounding the measurement, conversion and translation of value into economic outcomes [36-38]. It is not the intention of this calculator to overestimate outcomes or in the interest of sustainability of engagement for users to receive an inflated savings figure which may not be realised. For this reason, only business estimates from absenteeism and staff turnover were considered and the most conservative estimates were utilised when average ranges were reported.

The authors further acknowledge that estimating economic savings from productivity loss, even with the exclusion of a measure for presenteeism, remains debatable due to the wide variability, large influence on saving outputs, and issues surrounding use of indirect costs such as double counting and perspective [39]. Therefore the computed savings estimate from the Workplace Health Savings Calculator should not be considered to have utility in a health economic evaluation of workplace health promotion program. It is not an assessment or evaluation tool, rather an engagement tool to support workplace health and wellbeing efforts. The intended design and application is to engage businesses who are seeking an instrument to develop commitment at a stakeholder level.

Furthermore, the Workplace Health Savings Calculator is not a return on investment tool. It does not give the option to quantify program costs and therefore does not estimate net benefits or utilise cost benefit analysis techniques.

The United Kingdom PriceWaterhouseCoopers' review [21] was considered to have a strong methodological approach for the reported business outcomes, with its published effectiveness data also being used to support the Workplace Wellbeing Charter, National Award for England. The authors believe this review represented the best evidence base. In a field known to be lacking in robust quantifiable effectiveness and economic data, the authors recognise the lack of a more scientific approach compromises the validity of the calculator however consider the findings from the case studies to be real world representation and their use in this tool a pragmatic application.

Moreover, the NICE model from where the Workplace Health Savings Calculator was adapted is available as a business case tool within the NICE guidelines [PH13] for promoting physical activity at work. In December 2014 the guidelines underwent a second three-yearly review and the concluding decision states "no new evidence was identified which appeared to contradict the existing recommendations" [40]. Reliability and validity are cornerstone principles to scientific method, and although a gross limitation to the calculator is the fact that neither has been tested, the continued and ongoing expert opinion accepts such limitations due in part to a lack of rigorous evaluation designs, and the complexities and heterogeneities surrounding this public health intervention. 
In terms of generalisability, the research evidence used for change estimates was generated from an international (UK) context not an Australian setting where the calculator is applied. It is therefore unknown whether the effect size is transferable to locally-implemented interventions. However, we demonstrated that business sector statistics, workplace health strategies and practices, and the overarching political agenda focused on promoting health in the workplace to address rising prevalence of chronic disease is similar between both countries. Baseline prevalence, characteristics of the target population and capacity to implement interventions are key attributes for transferability in evidence-based public health [41].

From the initial data on organisational profile collected by the online Workplace Health Savings Calculator there has been a large proportion of SME interest. Australia defines a SME as a business employing 0-199 workers (small represents 0-19 employees and medium represents 20-199 employees [24]), and SMEs make up $99.7 \%$ of the Australian business sector [42]. This is comparable in both proportion and definition to United Kingdom, where SMEs are "businesses with zero to 249 employees, (which) account for 99.9 per cent of all enterprises" [43]. Interestingly, of the 55 case studies in the source review, only seven $(13 \%)$ were SMEs, representing manufacturing, financial, business services and retail sectors. The approximate size for all other organisations ranged from 200 to $100,000+$, the largest being the public sector service organisation. The low representation by small-to-medium business in the review could indicate a general lack of engagement or lack of resources. Nevertheless, in jurisdictions and regions where the business profile differs, for example in Tasmania, Australia (where the vast majority of SMEs are small businesses (94.8\%), with $58.8 \%$ being non-employing businesses and $36 \%$ employing 0-19 workers [42, 44]), a declaration of company size from where estimates originated should be made within the calculator.

Workplace health promotion is a modern corporate strategy, and for countries like Australia, it is a recognised public health initiative aimed at improving employee health and wellbeing. Calculators to assist in business justification are needed to develop stakeholder commitment and are seen as suitable to engage business in conversation for promoting health in the workplace. Other currently available online calculators lack generalisability to the Australian business market. Limitations surround country specificity, currency, complexity and appropriate evidence transferability. In contrast, the Workplace Health Savings Calculator is a practical easy-to-use business case tool that was developed in line with one of the core principles of the National Partnership Agreement on Preventive Health, and is to be used to support, engage and promote the implementation of healthy lifestyle programs in Australian workplaces.

\section{Availability and requirements}

Project name: Workplace Health Savings Calculator

Project home page: http://www.healthyworkers.gov. $\mathrm{au}$ and direct link available at: http://www.healthyworkers.gov.au/internet/hwi/publishing.nsf/Content/ roi-introduction

Operating system(s): Platform independent

Programming language: HTML

Other requirements: Nil

Any restrictions to use by non-academics: None (free to access).

\section{Availability of supporting data}

The data supporting the results of this article are included within the article and its additional files.

\section{Abbreviations}

SME: Small to medium enterprise; WHO: World Health Organisation; UK: United Kingdom; NICE: National Institute for Health and Clinical Excellence.

\section{Authors' contributions}

SB contributed with the development of the calculator and drafted the manuscript. SC assisted with the original policy-level idea, the development of the calculator and helped draft the manuscript. KS contributed with the original idea and assisted with progression and improvements to the calculator development, and helped improve the manuscript. CC assisted with progression of the calculator to the national platform, and helped improve the manuscript. AV contributed to the policy-research partnership (outlined below under Acknowledgements), assisted with improvements to the calculator, and helped improve the manuscript. CO assisted with formation of the policy-research partnership. AP assisted with improvements to the calculator and manuscript. All authors read and approved the final manuscript.

\section{Authors' information}

$\mathrm{SB}$ is a graduate research $\mathrm{PhD}$ candidate, $\mathrm{KS}$ is an associate professor, and $\mathrm{AV}$ and AP are professors at the Menzies Institute for Medical Research, an institute of the University of Tasmania. They are investigators in a large evaluation known as partneringHealthy@Work, within which the economic case for a workplace health and wellbeing program implemented by the Tasmanian State Government for the Tasmanian public service employees is being assessed. In the Tasmanian Government Department of Health and Human Services, SC is a Healthy Workers Initiative project officer, CC is the Healthy Workers Initiative program manager and $\mathrm{CO}$ is the project sponsor and deputy director of Population Health and Wellbeing (within Population Health Services).

\section{Author details}

${ }^{1}$ Menzies Institute for Medical Research, University of Tasmania, Medical Science 2 Building, 17 Liverpool St, Private Bag 23, Hobart, TAS 7000, Australia. 2 Population Health Services, Department of Health and Human Services (DHHS), 2/25 Argyle St, GPO Box 125, Hobart, TAS 7001, Australia.

\section{Acknowledgements}

This study was supported by a partnership research grant from the National Health and Medical Research Council Partnership Projects (Australia); NHMRC grant No H0010501, and additionally through the National Partnership

Agreement on Preventive Health, Healthy Workers Initiative-a joint Australian and Tasmanian Government initiative. The partnership grant supported the partnering Healthy@Work project, an investigator team drawn from the Menzies Institute for Medical Research, the University of Tasmania, and leading 
practitioners and policy makers from within the Tasmanian State Government, which was established to evaluate a workplace health promotion program implemented for Tasmanian public service employees. Furthermore the partnership project provided policy-research collaboration between researchers (Menzies Institute for Medical Research) and policy makers within Population Health Services at the Tasmanian Government Department of Health and Human Services. This afforded a three month (100 h) practical placement for one of the partnership PhD students (author SB) to provide additional research resources to the Department of Health and Human Services Healthy Workers Initiative team (authors SC, CC, CO) to assist in the development of the Healthy Workplace Resource Toolkit. Moreover, this placement provided a working example of a public service orientated research-policy alliance for authors SB and SC, and demonstrated a positive example of the value of partnership in translational research. Ethics approval for the student placement was granted by the Social Science Human Research Ethics Committee (Tasmania) Network.

\section{Compliance with ethical guidelines}

\section{Competing interests}

The authors Siyan Baxter, Sharon Campbell, Kristy Sanderson, Carl Cazaly, Alison Venn, Carole Owen and Andrew Palmer declare that they have no financial competing interests. The tool remains the non-financial intellectual property interest of the University of Tasmania and the Tasmanian Government.

\section{Received: 8 August 2014 Accepted: 31 August 2015} Published online: 18 September 2015

\section{References}

1. Chu C, Breucker G, Harris N, Stitzel A, Gan X, Gu X, Dwyer S. Health-promoting workplaces -international settings development. Health Promot Int. 2000;15(2):155.

2. WHO Global Plan of Action on Workers'Health. http://apps.who.int/gb/ ebwha/pdf_files/WHA60/A60_R26-en.pdf (2008-2017). Accessed 17 Apr 2014.

3. The European Network for Health Promotion (ENWHP). http://www. enwhp.org/publications.html. Accessed 10 Apr 2014

4. Health at work network of the public health responsibility deal. http:// www.dh.gov.uk/en/Publichealth/Publichealthresponsibilitydeal/index. htm. Accessed 10 Apr 2014.

5. Department of Health_UK. The NHS Health and Well Being Improvement framework, Department of Health. http://www.dh.gov.uk/prod_consum_dh/groups/dh_digitalassets/documents/digitalasset/dh_128813. pdf (2011). Accessed 5 Dec 2013.

6. National Health Service (NHS). Workplace Wellbeing Charter, National Award for England. http://wellbeingcharter.org.uk. Accessed 5 Dec 2013.

7. Patient Protection and Affordable Care Act 2010. Subtitle D-Provisions Relating to Title IV. HR 3590 EAS/PP. http://www.hhs.gov/healthcare/ rights/law/title/iv-amendments.pdf. Accessed 5 Mar 2014.

8. Australian Government Department of Health and Ageing; National Partnership Agreement on Preventive Health (NPAPH). http://www. health.gov.au/internet/main/publishing.nsf/Content/phd-prevention-np. Accessed 11 Oct 2011.

9. World Economic Forum: The New Discipline of Workforce Wellness Enhancing Corportae Performance by Tackling Chronic Disease. 2010.

10. Lerner D, Rodday AM, Cohen JT, Rogers WH. A systematic review of the evidence concerning the economic impact of employee-focused health promotion and wellness programs. J Occup Environ Med. 2013;55(2):209-22.

11. Malik SH, Blake H, Suggs LS. A systematic review of workplace health promotion interventions for increasing physical activity. Br J Health Psychol. 2014;19(1):149-80.

12. Rongen A, Robroek SJW, van Lenthe FJ, Burdorf A. Workplace health promotion: a meta-analysis of effectiveness. Am J Prev Med. 2013;44(4):406-15.

13. Osilla KC, Van Busum K, Schnyer C, Larkin JW, Eibner C, Mattke S. Systematic review of the impact of worksite wellness programs. Am J Manag Care. 2012;18(2):e68-81.
14. Baxter S, Sanderson K, Venn AJ, Blizzard CL, Palmer AJ. The relationship between return on investment and quality of study methodology in workplace health promotion programs. Am J Health Promot. 2014;28(6):347-63.

15. Faragher EB, Cass M, Cooper CL. The relationship between job satisfaction and health: a meta-analysis. Occup Environ Med. 2005;62(2):105-12.

16. Goetzel RZ, Pei X, Tabrizi MJ, Henke RM, Kowlessar N, Nelson CF, Metz $\mathrm{RD}$. Ten modifiable health risk factors are linked to more than one-fifth of employer-employee health care spending. Health Aff Millwood. 2012;31(11):2474-84.

17. Williden M, Schofield G, Duncan S. Establishing links between health and productivity in the New Zealand workforce. J Occup Environ Med. 2012;54(5):545-50.

18. Workplace Well-being Tool. http://www.dwp.gov.uk/health-work-andwell-being/our-work/workplace-well-being-tool/Published. Accessed 8 July 2013.

19. National Institute for Health and Clinical Excellence. Promoting physical activity in the workplace: business case. http://guidance.nice.org.uk/ PH13/BusinessCase/xls/English (2008). Accessed 23 Dec 2011.

20. WEF World Economic Forum. Workplace Wellness App developed by Boston Consulting Group. http://wellness.weforum.org/model. Accessed 23 Dec 2011.

21. PricewaterhouseCoopers LLP. Building the case for wellness, London: PWC. http://www.dwp.gov.uk/docs/hwwb-dwp-wellness-report-public. pdf (2008). Accessed 23 Dec 2011.

22. Grossmeier J, Terry PE, Cipriotti A, Burtaine JE. Best practices in evaluating worksite health promotion programs. Am J Health Promot. 2010;24(3):TAHP1-9 (iii).

23. Australian Government Department of Health and Aging, iii: Joint Statement of Commitment: Promoting good heath at work. Canberra, ACT; 2011.

24. Australian Government: Department of Innovation Industry Science and Research: Key statistics: Australian small businesses. Canberra ACT; 2011.

25. Buck Consultants LLP: Working Well: A Global survey of health promotion, workplace wellness and productivity strategies, 6th edn. 2014.

26. Australian Bureau of Statistics. Regional wage and salary earner statistics (Cat. No. 5673.0.55.003). Canberra: ABS; 2008.

27. Australian Human Resources Institute: HR Pulse 2008, 'Love 'em don't lose 'em'-identifying retention strategies that work. In. Melbourne, VICTORIA; 2008. http://www.ahri.com.au/MMSdocuments/profdevelopment/ research/research_papers/0803_pulse_vol2_no1_love_em_don't_lose_ em_web.pdf

28. WorkSafe Tasmania. www.worksafe.tas.gov.au/industry_and_safety/ health_and_wellbeing/simple_guide_resources. Accessed 17 March 2015.

29. Healthier Workplace WA: Workplace Health Savings Calculator. http:// www.healthierworkplacewa.com.au/learn/workplace-health-savingscalculator. Accessed 19 March 2015.

30. Better Work Tasmania: Workplace health and savings calculator. http:// www.betterwork.tas.gov.au/membership_benefits_-_public_promotional_information/workplace_health_and_savings_calculator. Accessed 19 March 2015.

31. Schultz AB, Edington DW. Employee health and presenteeism: a systematic review. J Occup Rehabil. 2007;17(3):547-79.

32. Johns G. Presenteeism in the workplace: a review and research agenda. J Organ Behav. 2010;31(4):519-42.

33. Goetzel RZ, Long SR, Ozminkowski RJ, Hawkins K, Wang S, Lynch W. Health, absence, disability, and presenteeism cost estimates of certain physical and mental health conditions affecting U.S. employers. J Occup Environ Med. 2004;46(4):398-412.

34. Burton WN, Chen CY, Conti DJ, Schultz AB, Pransky G, Edington DW. The association of health risks with on-the-job productivity. J Occup Environ Med. 2005;47(8):769-77.

35. Cancelliere C, Cassidy JD, Ammendolia C, Cote P. Are workplace health promotion programs effective at improving presenteeism in workers? A systematic review and best evidence synthesis of the literature. BMC public health. 2011;11:395.

36. Brooks A, Hagen SE, Sathyanarayanan S, Schultz AB, Edington DW. Presenteeism: critical Issues. J Occup Environ Med. 2010;52(11):1055-67. 
37. Koopmanschap M, Burdorf A, Jacob K, Meerding WJ, Brouwer W, Severens $H$. Measuring productivity changes in economic evaluation: setting the research agenda. Pharmacoeconomics. 2005;23(1):47-54.

38. Zhang W, Bansback N, Anis AH. Measuring and valuing productivity loss due to poor health: a critical review. Soc Sci Med. 2011;72(2):185-92.

39. Drummond MF, Sculpher MJ, Torrance GW. Methods for the economic evaluation of health care programmes. 3rd ed. USA: Oxford University Press; 2005.

40. National Institute for Health and Clinical Excellence: Promoting physical activity in the workplace: review decision document (2014). http://www nice.org.uk/guidance/ph13/documents. Accessed 14 March 2015.

41. Wang S, Moss JR, Hiller JE. Applicability and transferability of interventions in evidence-based public health. Health Promot Int. 2006;21(1):76-83.

42. Australian Bureau of Statistics. Counts of Australian businesses, including entries and exits, June 2007 until June 2011 (Cat. No. 8165.0). Canberra: ABS; 2012.

43. British Government: Department for Business Innovation and Skills: annual small business survey 2007/08. In: Williams MC editor, Department of Business Enterprise and Regulatory Reform; 2009.

44. Australian Bureau of Statistics. State and territory statistical indicators. Canberra ACT: ABS; 2011.
45. Department of Business Innovation and Skills. Small and medium-sized enterprise (SME) statistics for the UK and regions 2009. London: Government of the United Kingdom; 2010.

46. Australian Bureau of Statistics. Year Book Australia (Cat. No. 1310.0). Canberra ACT: ABS; 2006.

47. Australian Bureau of Statistics. Year Book Australia, Population projections - a tool for examining population ageing (Cat. No. 13010). Canberra ACT: ABS; 2008.

48. Australian Bureau of Statistics: Population projections, Australia, 2006 to 2101 (Cat. No. 3222.0). sCanberra, ACT; 2008.

49. Australian Bureau of Statistics. Population projections - a tool for examining population aging (Cat No 13011) Year Book Australia. Canberra ACT: ABS; 2008.

50. British Government Department for Work and Pensions: Welfare reform http://www.webarchive.nationalarchives.gov.uk/20130128102031 http:// www.dwp.gov.uk/welfarereform/c4.asp (2007).

51. PricewaterhouseCoopers and Medibank Health Solutions: Workplace wellness in Australia; aligning action with aims: Optimising the benefits of workplace wellness. http://www.pwc.com.au (2010).

\section{Submit your next manuscript to BioMed Central and take full advantage of:}

- Convenient online submission

- Thorough peer review

- No space constraints or color figure charges

- Immediate publication on acceptance

- Inclusion in PubMed, CAS, Scopus and Google Scholar

- Research which is freely available for redistribution

Submit your manuscript at

www.biomedcentral.com/submit

C Biomed Central 